\title{
HUBUNGAN DISIPLIN KERJA DAN MOTIVASI KERJA TERHADAP KINERJA PEGAWAI DI WILAYAH KERJA PUSKESMAS TANJUNG MORAWA
}

\section{INDAH PERMATASARI ${ }^{1}$, MAFE ROBBI SIMANJUNTAK², TARIANNA GINTING $^{3}$}

\author{
1,2,3 UNIVERSITAS PRIMA INDONESIA \\ Jalan Sekip Simp.Sikambing, Sei Putih Timur I, Kec. Medan Petisah, Kota \\ Medan, Sumatera Utara 20111 \\ e-mail : sarry.indah@yahoo.com
}

DOI : $10.35451 / j k f . v 3 i 1.529$

\begin{abstract}
Puskesmas is a place for health services in the form of health development which is accountable to the technical implementation unit at the Regency or City Service. Motivation and work discipline are factors that affect employee performance. Employee performance is tangible behavior displayed by employees as work performance that is generated in accordance with their position in the workplace. This research method using cross sectional design with a total sampling of 50 respondents. In the data collection method using primary data where the data is obtained from interviews through questionnaires to respondents and secondary data covering all employees of the Tanjung Morawa Public Health Center.The results of the study using the Chi-Square test can be seen from the results of statistical tests for the variable work discipline on employee performance, the $p$ value is $0.02<0.05$, which means that there is a relationship between work discipline and employee performance, the results of statistical tests for work motivation variables. the $p$ value obtained for performance is $1.00>0.05$, which means there is no relationship between work motivation and employee performance. It is hoped that the next researcher can change the object of research. In this case, it is necessary to carry out further research on the relationship between work motivation and performance in the Tanjung Morawa Public Health Center. in order to see the true relationship between motivation and employee performance.
\end{abstract}

Keywords: Motivation, discipline, employee performance

\section{Pendahuluan}

Puskesmas adalah suatu tempat pelayanan kesehatan yang berupa pembangunan kesehatan yang bertanggung jawab unit pelaksana teknis Dinas Kabupaten atau Kota (Depkes RI, 2011).
Kinerja pegawai ialah prestasi pekerjaan seorang karyawan kualitas dan kuantitas berupa suatu barang dan jasa melalui proses kerja dalam melakukan pekerjaan dengan tanggung jawab terhadapnya (Mangkunegara, 2010). 
Berdasarkan capaian penilaian prestasi kerja pada tahun 2015 terdapat 8 pegawai berada pada rentang nilai di bawah 79-90 dapat di lihat pada rentang nilai $<50$. Pada tahun 2016 mengalami peningkatan dengan total sebanyak 10 pegawai mengalami peningkatan ke rentang 7690 dan rentang nilai 91-ke atas. Pada tahun 2017 mengalami penurunan tingkat kinerja sebanyak 4 pegawai dari rentang 91-ke atas beralih ke rentang 76-90 dapat di artikan bahwa pada tahun 2017 sebanyak 4 pegawai mengalami penurunan dalam penilaian prestasi kerja (Dinas Kesehatan Jawa Barat, 2017).

Berdasarkan hasil survei awal yang saya dapat di Puskesmas Tanjung Morawa, setelah membagikan kuesioner kepada beberapa pegawai dari 50 pegawai yang ada di puskesmas tersebut. Saya mendapatkan masalah bahwa pegawai tidak bertanggung jawab pada pekerjaannya sehingga masih ada pegawai yang memberikan pelayanan tidak tepat waktu kepada pasien, pegawai juga tidak menerapkan hasil pelatihannya yang sudah di jalankan sehingga masih ada pegawai yang belum optimal dalam memberikan sosialisasi kesehatan terhadap masyarakat (Puskesmas Tanjung Morawa, 2020).

$\mathrm{Di}$ katakan disiplin bermutu memperoleh menciptakan komitmen individu akan pekerjaan yang di berikan untuknya, agar dapat meningkatkan kinerja yang baik dan dapat mewujudkan tujuan organisasi karyawan serta masyarakat (Rivai, 2010). Hal tersebut tidak sejalan dengan teori tersebut mengungkapkan disiplin bermutu dapat menciptakan komitmen individu akan pekerjaan di berikan untuknya. Sehingga asumsi peneliti di lihat disiplin puskesmas tersebut kurang mencerminkan rasa tanggung jawab terhadap tugas yang di berikan, ketidak tepatan waktu dalam menyelesaikan tugas, selain itu mayoritas pekerja berusia 41-49 tahun dan tidak adanya pelatihan dalam mengoprasikan peralatan kantor sehingga menjadikan penghambat dalam menyelesaikan tugas.

Motivasi yang kuat dapat menciptakan hasil dan kinerja yang berkualitas terhadap tugas yang telah di lakukan oleh pegawai, sehingga dapat meningkatkan motivasi terhadap pegawai dalam pekerja dan mencapai tujuan tersebut. Hal tersebut tidak sejalan dengan teori tersebut menyatakan bahwa motivasi yang kuat dapat menciptakan hasil dan kinerja yang berkualitas. Sehingga asumsi peneliti di lihat motivasi puskesmas kurang mencerminkan rasa tanggung jawab terhadap tugas yang di berikan, selain itu pegawai juga tidak tepat waktu dalam menyelesaikan tugas yang di berikan oleh atasan dan pegawai kurang mengikuti kegiatan pelatihan yang telah di lakukan di puskesmas (Latif,2012).

\section{METODE}

Penelitian ini merupakan survei analitika bertujuan agar memahami hubungan disiplin kerja dan motivasi kerja terhadap kinerja pegawai.

Rancangan Penelitian ini merupakan cross sectional bertujuan agar memahami hubungan disiplin kerja dan motivasi kerja terhadap kinerja pegawai.

Cara pengutipan sampel di dalam penelitian menggunakan total sampling, di mana total sampling ialah pengutipan sampel terhadap seluruh komunitas penelitian yang berjumlah 50 pegawai di wilayah kerja Puskesmas Tanjung Morawa (Sugiyono, 2016).

\section{HASIL}


Analisis Univariat berdasarkan hasil penelitian, data di kumpulkan ke dalam bentuk tabel untuk menyederhanakan setiap variabel yang di teliti. Hasil pengumpulan data di kumpulkan melalui kuisioner yang di bagikan kepada responden dalam tabel berikut :

Tabel 3.1. Distribusi Frekuensi Berdasarkan Umur

\begin{tabular}{|c|c|c|}
\hline $\begin{array}{c}\text { Karakteristik } \\
\text { umur }\end{array}$ & Jumlah & $\%$ \\
\hline 23-31 tahun & 6 & 12 \\
\hline $32-40$ tahun & 13 & 26 \\
\hline 41-49 tahun & 21 & 42 \\
\hline 50-58 tahun & 10 & 20 \\
\hline Total & 50 & 100 \\
\hline
\end{tabular}

peroleh hasil distribusi frekuensi Umur Pegawai Puskesmas mayoritas berumur 41 - 49 Tahun sebanyak 21 orang $(42 \%)$, dan minoritas berumur $23-31$ Tahun sebanyak 6 orang (12\%).

Tabel 3.2. Distribusi Frekuensi Berdasarkan Jenis Kelamin

\begin{tabular}{ccc}
\hline $\begin{array}{c}\text { Karakteristik } \\
\text { Jenis } \\
\text { Kelamin }\end{array}$ & Jumlah & $\%$ \\
\hline Laki-laki & 1 & 2 \\
Perempuan & 49 & 98 \\
\hline Total & 50 & 100 \\
\hline
\end{tabular}

Berdasarkan Tabel 3.2. diperoleh hasil distribusi frekuensi jenis kelamin Pegawai Puskesmas laki - laki sebanyak 1 orang (2\%), dan Perempuan sebanyak 49 orang (98\%).

Tabel 3.3. Distribusi Frekuensi Berdasarkan Pendidikan

\begin{tabular}{ccc}
\hline $\begin{array}{c}\text { Karakteristik } \\
\text { Pendidikan }\end{array}$ & Jumlah & $\%$ \\
\hline D3 & 29 & 58 \\
S1 & 17 & 34 \\
S2 & 4 & 8 \\
\hline Total & 50 & 100 \\
\hline
\end{tabular}

Berdasarkan Tabel 3.3. di peroleh hasil distribusi frekuensi Pendidikan
Pegawai Puskesmas mayoritas D3 sebanyak 29 orang (58\%), dan minoritas sebanyak 4 orang ( $8 \%)$.

Tabel 3.4. Distribusi Frekuensi Berdasarkan Pekerjaan

\begin{tabular}{|c|c|c|}
\hline $\begin{array}{c}\text { Karakteristik } \\
\text { Pekerjaan }\end{array}$ & Jumlah & $\%$ \\
\hline PNS & 48 & 96 \\
\hline Honorer & 2 & 4 \\
\hline Total & 50 & 100 \\
\hline
\end{tabular}

Berdasarkan Tabel 3.4. di peroleh hasil distribusi frekuensi Pegawai Negeri Sipil sebanyak 48 orang (96\%), sebanyak 2 orang (4\%)

Analisis Bivariat merupakan analisis lanjutan mengetahui hubungan disiplin kerja dan motivasi kerja terhadap kinerja pegawai di Wilayah kerja Puskesmas Tanjung Morawa. Analisis yang di gunakan adalah analisis chi square. Maka hasil analisisnya sebagai berikut :

Tabel 3.5. Hubungan disiplin kerja dan motivasi kerja terhadap kinerja pegawai di wilayah kerja Puskesmas Tanjung Morawa

\begin{tabular}{llll}
\hline $\begin{array}{c}\text { Disiplin } \\
\text { Kerja }\end{array}$ & Kinerja pegawai & Total \\
\hline & Baik Buruk N $\%$
\end{tabular}

\begin{tabular}{ccccc}
\hline Disiplin & 5 & 38 & 43 & $86 \%$ \\
\hline $\begin{array}{c}\text { Tdk } \\
\text { Disiplin }\end{array}$ & 5 & 2 & 7 & $14 \%$ \\
\hline Total & 10 & 40 & 50 & $100 \%$ \\
\hline$P-$ & & & & 0,02
\end{tabular}

value

Dari tabel 3.5. responden yang memiliki disiplin kerja yang baik sebanyak 43 orang (86\%), mayoritas pegawai yang memiliki kinerja yang baik sebanyak 5 orang $(11,7 \%)$, minoritas pegawai yang memiliki kinerja yang buruk sebanyak 38 orang $(88,3 \%)$. 
Dari tabel 3.5. responden yang memiliki disiplin yang kurang sebanyak 7 orang (14\%), mayoritas pegawai yang memiliki kinerja yang baik sebanyak 5 orang $(71,4 \%)$, minoritas pegawai yang memiliki kinerja yang buruk sebanyak 2 orang $(28,6 \%)$.

Tabel 3.6. Hubungan disiplin kerja dan motivasi kerja terhadap kinerja pegawai di wilayah kerja Puskesmas Tanjung Morawa

\begin{tabular}{ccc}
\hline $\begin{array}{c}\text { Motivasi } \\
\text { kerja }\end{array}$ & Kinerja pegawai & Total \\
\end{tabular}

\begin{tabular}{ccccl}
\hline & Baik & Buruk & $\mathrm{N}$ & $\%$ \\
\hline Disiplin & 7 & 27 & 34 & $68 \%$ \\
\hline $\begin{array}{c}\text { Tdk } \\
\text { Disiplin }\end{array}$ & 3 & 13 & 16 & $32 \%$ \\
\hline Total & 10 & 40 & 50 & $100 \%$ \\
\hline$P$-value & & & & 1,00
\end{tabular}

Dari tabel 3.6. responden yang memiliki motivasi kerja yang baik sebanyak 34 orang (68\%), mayoritas pegawai yang memiliki kinerja yang baik sebanyak 7 orang $(20,6 \%)$, minoritas pegawai yang memiliki kinerja yang buruk sebanyak 27 orang $(79,4 \%)$.

Dari tabel 3.6. responden yang memiliki motivasi yang kurang sebanyak 16 orang (14\%), mayoritas pegawai yang memiliki kinerja yang baik sebanyak 3 orang $(18,8 \%)$, minoritas pegawai yang memiliki kinerja yang buruk sebanyak 13 orang $(81,2 \%)$.

\section{PEMBAHASAN}

Hubungan disiplin kerja terhadap kinerja pegawai di wilayah kerja Puskesmas Tanjung Morawa.

Menurut hasil penelitian telah melakukan uji Chi-Square Test di peroleh nilai $p$ value $0,02<0,05$ maka ada hubungan disiplin kerja terhadap kinerja pegawai di wilayah kerja puskesmas tanjung morawa.

Berdasarkan hasil penelitian yang telah dilakukan oleh (Usman, 2016) terhadap disiplin kerja pegawai dengan kinerja pegawai, di peroleh hasil nilai $p=0,000$ sehingga $p<0,05$ maka Ho di tolak ada hubungan disiplin dengan kinerja pegawai di Puskesmas Lapadde Kota Parepare.

Penelitian yang dilakukan (Kasim, Robot, \& Hamel, 2013) terhadap variabel disiplin waktu menggunakan uji Statistik menunjukkan nilai $\rho=0,017<0,05$ yang berarti ada hubungan Disiplin Waktu dengan Kinerja Pelayanan Kesehatan di Puskesmas Tataba Kec. Buko Kabupaten Banggai Kepulauan.

Hal tersebut dapat terjadi karena asumsi peneliti di lihat dari disiplin puskesmas tersebut kurang mencerminkan rasa tanggung jawab terhadap tugas yang di berikan, sehingga tidak tepat waktu dalam menyelesaikan tugas, selain itu mayoritas pekerja berusia 41-49 tahun dan tidak adanya pelatihan dalam mengoprasikan peralatan kantor sehingga menjadi penghambat dalam menyelesaikan tugas dan kurangnya pegawasan dari atasan.

Hubungan motivasi kerja terhadap kinerja pegawai di wilayah kerja Puskesmas Tanjung Morawa.

Menurut hasil penelitian dengan menggunakan uji Chi-Square Test di peroleh nilai $p$ value $1,00>0,05$ maka tidak ada hubungan motivasi kerja terhadap kinerja pegawai di wilayah kerja Puskesmas Tanjung Morawa.

Berdasarkan hasil penelitian yang telah di lakukan oleh (Usman, 2016) terhadap motivasi dengan kinerja pegawai, di dapatkan hasil nilai $\rho=$ $0,001<0,05$ maka Ho pada penelitian 
ini di tolak, artinya ada hubungan motivasi dengan kinerja pegawai di Puskesmas Lapadde Kota Parepare.

Hasil penelitian ini sejalan juga dengan penelitian yang di lakukan (Wahyudi, Salham, \& Kadri, 2018) variabel motivasi menunjukkan nilai $\rho$ $=0,008<\rho=0,05$. Hal ini menunjukkan bahwa ada hubungan variabel motivasi berhubungan dengan Kinerja Petugas Kesehatan Pelayanan Manajemen Terpadu Balita Sakit Di Puskesmas Kamonji Kota Palu.

Hal tersebut tidak sejalan dengan penelitian di lakukan penelitian (Usman, 2016) terhadap motivasi dengan kinerja pegawai di dapatkan hasil bahwa ada hubungan motivasi dengan kinerja. Sehingga asumsi peneliti di lihat motivasi puskesmas kurang mencerminkan rasa tanggung jawab terhadap tugas yang di berikan, selain itu pegawai juga tidak tepat waktu dalam menyelesaikan tugas yang di berikan oleh atasan dan pegawai kurang mengikuti kegiatan pelatihan yang telah di lakukan di puskesmas.

\section{KESIMPULAN}

1. Sebagai bahan masukan dan kajian kepada Puskesmas Tanjung Morawa untuk meningkatkan disiplin kerja dan motivasi kerja terhadap kinerja pegawai pada wilayah kerja Puskesmas Tanjung Morawa.

2. Di harapkan menjadi masukan untuk meningkatkan disiplin kerja dan motivasi kerja terhadap kinerja pegawai Puskesmas Tanjung Morawa.

3. Diharapkan hasil penelitian ini dapat di jadikan informasi dan bahan baca di perpustakaan dan memperbanyak materi perkuliahan tentang disiplin kerja dan motivasi kerja terhadap kinerja pegawai.

4. Selain itu, di harapkan bagi peneliti berikutnya dapat mengganti objek penelitian, kasus ini perlu di lakukan penelitian lanjut terhadap hubungan motivasi kerja dengan kinerja di Puskesmas Tanjung Morawa. Supaya dapat melihat adanya hubungan sebenarnya antara motivasi dengan kinerja pegawai.

\section{DAFTAR PUSTAKA}

Abdul Latif (2012). Obat Tradisional. Jakarta: EGC

A.A . Anwar Prabu Mangkunegara. (2010). Manajemen Sumber Daya Manusia Perusahaan. Bandung:PT Remaja Rosdakarya.

Depkes RI. (2011). Rencana Strategis Departemen Kesehatan. Jakarta.

Dinas Kesehatan. (2017). Dokumen Badan Kepegawaian Dinas Kesehatan Provinsi Jawa Barat.

Kasim, Robot, 2013, Hubungan Disiplin waktu dengan Kinerja Pelayanan Kesehatan di Puskesmaas Tataba Kec. Buko Kabupaten Banggai Kepulauan, Program Studi IImu Keperawatan Fakultas Kedokteran Universitas Sam Ratulangi Manado.

Puskesmas Tanjung Morawa. (2020). Puskesmas Tanjung Morawa.

Rivai, dkk. (2010). Manajemen Sumber Daya Manusia. 2010: PT. Raja Grafindo Persada.

Sugiyono. (2016). Metode Penelitian Kuantitatif, Kualitatif dan $R \& D$. Bandung:Alfabeta

Usman. (2016). Analis Kinerja Tenaga Kesehatan Pada Puskesmas Lapadde Kota Parepare, 12 (1), 21-28. 
Wahyudi, A., Salham, M., \& Kadri, A.

(2018). Faktor Yang Berhubungan

Dengan Kinerja Petugas

Kesehatan Pelayanan Manajemen

Terpadu Balita Sakit Di Puskesmas

Kamonji Kota Palu, 208-219. 


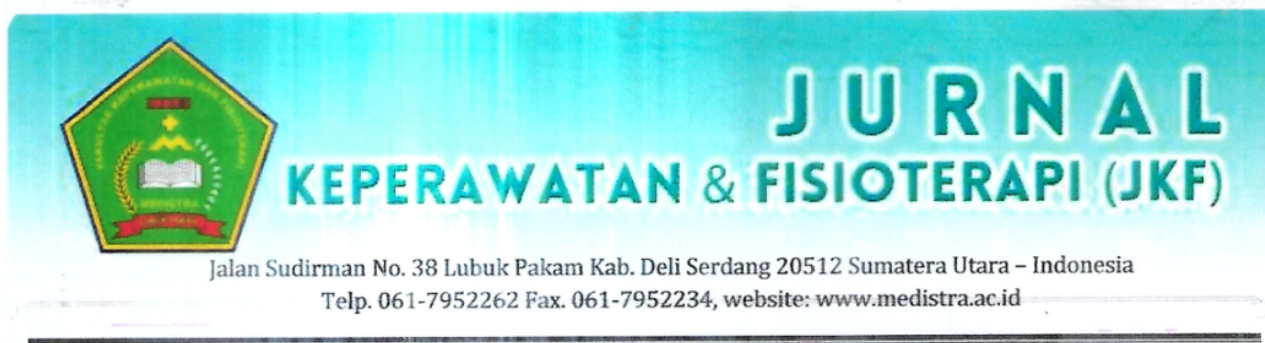

PERNYATAAN PENULIS

Saya yang bertanda tangan dibawah ini:

$\begin{array}{ll}\text { Nama } & \text { : Indah Permatasari } \\ \text { Institusi } & \text { : Universitas Prima Indonesia } \\ \text { Alamat } & \text { : Jl. Pukat Banting IV Gg. Teladan No.4 LK II } \\ \text { Email } & \text { : sarry.indah@yahoo.com } \\ \text { Judul Artikel } & \text { : Hubungan Disiplin Kerja dan Motivasi Kerja Terhadap Kinerja Pegawai } \\ & \text { Di Wilayah Kerja Puskesmas Tanjung Morawa }\end{array}$

Menyatakan bahwa saya (penulis) telah mengirimkan artikel dengan judul di atas ke Dewan Editorial Jurnal Keperawatan dan Fisioterapi (JKF) yang akan diterbitkan pada volume dan nomor berikutnya pada Jurnal Keperawatan dan Fisioterapi (JKF). Dengan ini saya mengkonfirmasi bahwa:

1. Artikel tersebut merupakan karya penulis dan belum pernah dipublikasikan oleh jurnal ilmiah lain.

2. Semua data, ide, dan pernyataan yang terkandung dalam artikel tersebut sepenuhnya menjadi tanggung jawab penulis.

3. Selama proses penulisan naskah ini, penulis tidak memiliki masalah atau konflik kepentingan dengan penulis bersama lainnya.

Saya menyatakan bahwa penyataan ini adalah benar dan sesuai dengan peraturan dan ketentuan JKF. Jika di masa depan ada kesalahan, penulis bersedia mempertanggungjawabkannya sesuai dengan undang-undang yang berlaku.

Medan, 20 Oktober 2020

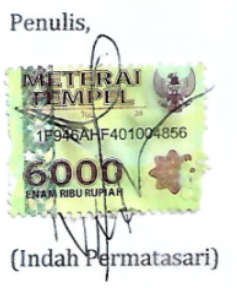

Catatan:

* Formulir Pernyataan ini diupload bersamaan dengan Manuskrip Jurnal 